\title{
The Impact of Peer Scaffolding through Process Approach on EFL Learners' Academic Writing Fluency
}

\author{
Masoud Khalili Sabet \\ English Department, University of Guilan, Rasht, Iran \\ Abdorreza Tahriri \\ English Department, University of Guilan, Rasht, Iran \\ Parastou Gholami Pasand \\ English Department, University of Guilan, Rasht, Iran
}

\begin{abstract}
This paper aimed to examine the impact of peer scaffolding through process approach on writing fluency of EFL learners. To this end, a Nelson Proficiency Test was administered to 49 EFL learners studying at University of Guilan, based on which $\mathbf{4 0}$ homogenous learners at an intermediate level comprised the research sample. Afterwards, the participants were randomly divided into a control group of 20 students, and an experimental group comprising 10 dyads. The control group wrote argumentative essays based on product approach to writing and those in the experimental group practiced essay writing through process approach while a competent writer provided scaffolding to a less competent one. The essays produced in pre- and posttest were analyzed in terms of writing fluency. Using SPSS 16, the results of One-way ANOVA at the alpha level of .05 revealed that in spite of having improvement in some aspects of their writing fluency such as words per minute, average words and T-units, learners in the experimental group did not outperform those in the control group. However, one-way Repeated Measures ANOVA illustrated that both competent and less competent writers in the experimental group have improved in their writing fluency. The study may have implications for improving EFL learners' fluency in writing.
\end{abstract}

Index Terms - academic writing, peer scaffolding, process approach, interaction, sociocultural theory, fluency

\section{INTRODUCTION}

Writing is one of the most important and challenging skills which involves a complicated process of generating ideas and translating them into written symbols. In recent years, the teaching of English as a Second or Foreign Language (TESL/TEFL) has witnessed a change in the theoretical and methodological perspectives from considering language learning as an individual accomplishment to understanding it as a social act. Particularly, this change is evident in the conception of writing skill in which interaction and collaboration have become the concern of many researchers (See for example Storch, 2005; 2007, Wiggleworth \& Storch, 2009).

Furthermore, recently scaffolding and the zone of proximal development (ZPD) have gained paramount attention in L2 learning studies. Initially used by Wood, Bruner and Ross (1976) in an analysis of children-tutor interaction, scaffolding was soon associated with Vygotsky's notion of ZPD. According to Donato (1994) the concept of scaffolding is derived from cognitive psychology and research in L1, and it refers to the supportive conditions made by a knowledgeable participant in a social interaction. Scaffolding and its relationship to second or foreign language learning has been studied in different aspects of interaction such as teacher-student or student-student interaction, called peer scaffolding.

As is stated by Mirzaee, Domakani and Roshani (2010), Sociocultural concepts have been a matter of neglect in Iran and most of the studies have been concerned with linguistic, cognitive and affective aspects of second language acquisition. More specifically, although the use of pair or group work is strongly advocated in EFL/ESL classrooms, these are not much applied to Iranian EFL classrooms, and in spite of many researches done in ESL/EFL writing pedagogy, writing is still one of the most difficult skills for language learners. One of the difficulties that most of the EFL learners complain or ask about when they are required to write an essay or composition is the amount or quantity of their writings. Due to the problems that most EFL learners face when writing individually, it seems to be more practical to engage the learners in pair writing during which competent peers scaffold and guide less competent ones.

Therefore, this paper aims at investigating the impact of peer scaffolding through process approach on the writing fluency of EFL learners. To this end the present research study addresses the following questions:

1- What is the impact of peer scaffolding through process approach on writing fluency of intermediate EFL learners? 
2- Does peer scaffolding through process approach have any influence on writing fluency of competent intermediate EFL writers?

3- Does peer scaffolding through process approach have any influence on writing fluency of less competent intermediate EFL writers?

Regarding the aforementioned research questions the following null hypotheses have been formulated:

$\mathrm{H}_{0}$ 1. Peer scaffolding through process approach has no impact on writing fluency of intermediate EFL learners.

$\mathrm{H}_{0}$ 2. Peer scaffolding through process approach has no impact on writing fluency of competent intermediate EFL writers.

$\mathrm{H}_{0}$ 3. Peer scaffolding through process approach has no impact on writing fluency of less competent intermediate EFL writers.

\section{THEORETICAL AND RESEARCH BACKGROUND}

\section{A. An Overview of Vygotsky's Sociocultural Theory}

Sociocultural Theory (SCT) is an approach to human sciences with the purpose of explaining and developing a connection between mental functioning and the cultural, institutional and historical conditions in which mental functioning happens (Van Lier, 2004 as cited in Pishghadam \& Ghadiri, 2011). It directly emphasizes the link between social context and individuals' psychological development (Bruffee, 1993, 1996; Gere, 1987 as cited in Tsai, 2006).

Vygotsky $(1978,1981$ \&1987) is fundamentally concerned with the thesis that the development of human cognitive functions proceeds from the social or interpsychological plane to the individual or intrapsychological plane, with the use of symbolic, socioculturally developed tools the most important of which is language. In other words, SCT regards human mental functioning as necessarily a mediated process which is organized by artifacts, activities and concepts (Lantolf, 2000). In addition, as Lantolf \& Thorne (2007) point out, although Vygotsky does not reject the neurobiological factors for the development of higher order thinking ability he mainly focuses on the significance of interaction occurring within social contexts for developing human cognitive ability. Generally, in SCT learners are treated as active meaning-makers and problem-solvers in their process of learning with the great emphasis on the learning which stems from interaction and negotiations of meaning among individuals.

The notion of ZPD is considered significant in SCT since it is the region in which the transition from interpsychological functions turns into intrapsychological functions. It is believed that a variety of internal developmental functions will be activated by learning and this process only happens provided that the child interacts with the peers or adults in a social environment (Fahim \& Haghani, 2012). However, it should be mentioned that the current view of the ZPD has been expanded beyond the interaction between an expert and a novice. Recent research seeks to gain a better understanding on how L2 learning is mediated in the ZPD by looking more closely at peer interactions in the ZPD. In other words, ZPD is considered as providing an opportunity to learn with and from others (Anton, 1999; Lantolf, 2000; Wells, 1998).

\section{B. Scaffolding}

Scaffolding was first associated with the ZPD; it was later used by Bruner (1978) as a metaphor for a mother's verbal assistance in maintaining conversation with a child and indirectly promoting language learning. It has also been applied in the context of tutorial interaction where a tutor helps a less skilled person to solve a problem (Hekamäki, 2005). Wood, Bruner and Ross (1976) used the term scaffolding as a metaphor to refer to a process whereby an adult assist a child to learn how to perform a task that she or he cannot perform alone. They describe the process of scaffolding as involving "the adult's controlling those elements of the task that are initially beyond the learner's capacity." (p. 90)

Accordingly, by scaffolding the learner will be enabled to complete those elements of the task that he or she may not be able to do without assistance. However, as Wood et al. (1976, p.90) further state, "the process can potentially achieve much more for the learner than an assisted completion of the task." And it eventually results in "development of task competence by the learner at a pace that would far outstrip his unassisted effort." (Ibid.) Furthermore, Walqui (2006) points out that scaffolding can be regarded as three related pedagogical scales. First, there is the meaning of providing a support structure to enable certain activities and skills to develop. Second, there is the actual carrying out of particular activities in class, and third, there is the assistance provided in moment-to-moment interaction.

As stated by Nguyen (2013), the term scaffolding has been interpreted and operationalized in various ways since its emergence. These varied interpretations have expanded the significance of scaffolding to the extent that who provides scaffolding is no longer a question and the focus has shifted from "expert" to "expertise". The use of scaffolding is no longer restricted to expert/novice interactions and many researchers have considered peer collaboration (e.g. Barnard, 2002; De Guerrero\& Villamil, 2000) in addition to interactions between a teacher and classroom (e.g. Riazi \& Rezaii, 2011) as scaffolding.

Van Lier (2004) lists six important features of scaffolding as follows:1- Continuity: repeated occurrence over time with variations connected to one another; 2- Contextual support: a safe but challenging environment, errors are expected as part of the learning process; 3- Intersubjectivity: mutual engagement and support, two minds thinking as one; 4- Flow: communication between participants is not forced but flows in a natural way; 5- Contingency: the 
scaffolding support depend on learners' reactions, elements can be added, changed, deleted, repeated, etc. 6Handover/Takeover: there is an increasing role for the learners when the skills and confidence increase.

\section{Review of Related Literature}

Sociocultural Theory and its related components of ZPD and scaffolding has gained unprecedented attention and become an appealing frame in educational contexts and especially in L2 studies. However, to date there are very few studies regarding the impact of peer scaffolding on the writing performance of EFL learners. Whereas most of the studies on scaffolding are concerned with teacher- student interactions, as Storch (2007) points out scaffolding can also occur when peers work together and interact in pairs or small groups.

Storch (1999) explored the impact of peer scaffolding on the students' language learning and found that collaboration has a positive impact on the overall grammatical accuracy of the learners when doing grammar focused exercises. As a result, it can be concluded that peer scaffolding leads to co-construction of knowledge by the learners and language development.

Storch (2005) also investigated the writing performance of 23 ESL students completing degree courses. Comparing texts produced by pairs with those written by individuals, the results showed that the pairs produced less fluent but better texts in terms of task fulfillment, complexity, and accuracy. However, in this study pairing was not done in a way that more competent writers work with less competent ones.

In another study, Wiggleworth and Storch (2009) investigated the use of collaborative writing on students' writing ability in terms of their writing fluency, accuracy and complexity. Although they found it effective on the learners' accuracy in writing, the results did not reveal a positive, effective influence on the learners' fluency and complexity of writing.

\section{Methodology}

\section{A. Participant}

The present study was carried out at Guilan University in Rasht, north of Iran. 49 university students (23 males and 26 females) were the potential participants of the study. After the test of proficiency 40 students ( 20 males and 20 females) were selected and randomly assigned to two groups, one experimental including 10 males and 10 females, and the other one control group consisting of 10 males and 10 females. The students were all freshmen majoring in English Language and Literature and they were in the second semester of their studying at university. The writing classes for both experimental and control groups were held once a week in 90 minutes. The age of the participants ranged from 17 to 32. The control group was taught based on the product approach to writing and the students wrote essays individually, while in the experimental peer scaffolding was conducted through process approach to writing.

\section{B. Instruments}

The first instrument used in this study was Nelson Proficiency Test (B). Some argumentative essay samples were also used during the teaching for the control group. Moreover, both experimental and control groups were provided with some pamphlets introducing the argumentative genre of writing. In addition, we made use of peer feedback sheets taken from the book Refining Composition Skills by Smalley, Ruetten, and Kozyrev (2001), in the experimental group. The topics were chosen considering students' interests, age and field of study.

\section{Procedure}

First, to ensure the homogeneity of the participants Nelson Proficiency Test (B) was administered to 49 students in the two classes in the first session and 40 students who were more or less at the same level of English proficiency were considered as the participants of the study. Then they were randomly assigned to experimental and control groups. In doing so it was tried to assign equal numbers of male and female students to each group. The second session in week 1 was spent informing the students of their proficiency test scores and dividing them into two groups.

In the second week, the first session in each class was spent making students familiar with the format of argumentative essay by lecturing and using pamphlets and handouts about how to write introduction, body paragraphs and conclusion. At the end of the session, a sample argumentative essay was also introduced and explained to learners in both groups.

In the third week, a pre-test was taken from both groups in the time limit of 45 minutes. The pre-test had two purposes. One of them was to be able to compare students' writing performance at the end of the classes, and the other purpose was to determine the competent and less competent learners in the experimental group in order to form dyads so that the more competent writers scaffold the less competent ones when writing essays. It needs to be mentioned that the selection of competent learners was based on their performance regarding the definition of writing fluency in this study as being able to write more in a limited time. In other words, those students who could write a full argumentative essay in shorter time with more number of words, clauses and T-units were considered to be fluent and more competent writers. Furthermore, pairing in the experimental group was done in such a way that females were paired together and males were also paired together. The next four weeks (weeks 4, 5, 6 and 6) were spent by having the control group to write based on the product approach and those in the experimental group to write on the basis of process approach to 
writing while each competent writer scaffolded his/her partner. In what follows a comprehensive description of the procedure in each group will be provided.

The teaching procedure in the control group started by a class discussion about the topic of the essay that the students were supposed to write in each session respectively. Then they were given a model essay and the main parts of the essay were analyzed in the class as a whole with students contributing and giving their idea about what should be written in each section of the essay such as the thesis statement, pro ideas, con ideas, and concluding remarks. This took about thirty to forty-five minutes of the class time in each session. After that the students were asked to produce an individually-written essay in the traditional way common to most Iranian contexts, similar to the model essay at hand within the remaining forty-five minutes. After submitting their essays they were provided with the teacher feedback mainly on the content and organization of their essays.

The teaching procedure in the experimental group inaugurated in the same fashion as in the control group by having a class discussion and brainstorming about the topic at hand in each session. The main difference was that in the control group students wrote their essays in pairs rather than individually and they went through the main phases of writing process as those offered by Seow (2002, as cited in Richards \& Renandya, 2002) including 1) planning, 2) drafting, 3) revising, and 4) editing. Since the students were not familiar with these satges a whole session was devoted to having them practice writing based on the process approach. Some points about the pair writing neeeds to be mentioned. First, the members of each dyad were assigned different roles. The competent writers had been given the role of a consultant or helper while the less competent writers were asked to take the responsibility of writing the essays,and they were given the role of the writer.Moreover, members of the dyads were chosen randomly by the researcher and since the stuents knew each other they were not reluctant to be paired with their classmates. In addition, both learners in each pair were asked to share their ideas in the planning, drafting, and revision phases of the writing. Also, the members were not told that one of them is more competent than the other, and peer scaffolding was conducted as the more competent learner took the role of the consultant. In addition, the scaffolding features, as observed by the researcher, in the experimental group as stated by Van Lier (2004) have been met as follows:

Contextual support was initially provided by the explanations and clarifications on the argumentative genre by the tutor and with the peer discussions between the members of the dyads. Another layer of the contextual support was created by the students themselves when deciding to argue for or against a topic and providing supports for their arguments. The challenge was to co-construct a five-paragraph argumentative essay in the limited time of classroom hour.

Continuity was met as every session the pairs were required to write a complete argumentative essay, building on their past knowledge of the genre which have been developed in the previous sessions. Out of class collaboration on revising their essays based on peers or teacher feedback and comments also enabled the learners to link the past and future interaction.

Intersubjectivity was achieved when the pairs engaged in harmonious exploratory talk in such cases as reformulating the statement made by one member of the dyad and seeking confirmation of his or her understanding. There was mutual engagement and support in each dyad as the members tried to pull on each other's linguistic and extra-linguistic knowledge of the mechanical as well as contextual aspects of the essay at hand. In this way they were involved in the knowledge transmission, receiving and taking suggestions and working toward a common goal, namely co-constructing a comprehensive essay.

Flow was achieved as the interaction between the peers in each dyad was the characteristic of easy, unforceful conversations. The peers addressed each other and talked comfortably when sharing ideas and discussing different aspects of their writing.

Contingency was met during drafting and revision phases of the writing process as the assistance provided by the more capable peer was contingent upon what has been done in the previous stages of the writing process, thus, elements were changed, added or deleted accordingly. More specifically in the drafting phase it was observed that the more capable peer who had taken the role of a consultant tried to build a trustful atmosphere ensuring the less competent peer that what he or she says regarding for instance spelling or choice of a particular term was right. This made the peers' varied comprehension and interpretation to be brought in the surface of discourse and it was reconstructed and refined through contingent interaction (Barnard \& Campbell, 2005).

Handover was employed when at the end of each writing task the peers reached agreement on what they were supposed to write in each section of the essay including introduction, body, and conclusion, or what should be added to them. Thus, before submitting their essay to the teacher, the learners achieved a measure of control over their writing process through interdependent activity. (Ibid.)

Furthermore, the students in the experimental group were asked to write a revised essay individually, since the ultimate purpose of scaffolding is being able to perform a task independently, or moving from interpsychological plane to intrapsychological plane. Like the control group, students in the experimental group were provided with teacher feedback on the content, organization of their essays in each session.

Finally, the last week was considered to take a post-test from each group. In the post-test students in each group were asked to individually write an argumentative essay in the same time limit as the pre-test that is in 45 minutes. 


\section{RESULTS}

Writing fluency in the study of Wigglesworth and Storch (2009) referred to the average number of words, Terminable Units (T-units) and clauses. Following Wigglesworth and Storch (2009), in our study fluency was measured in the same way. And as time is an important aspect of fluency, we also used Chenoweth and Hayes' (2001) measurement scale i.e. the number of words written per minute. For data analysis SPSS 16 was used.

To make sure that there is enough accuracy in the calculation of the number of words, T-units, clauses and words per minute, each essay in the pre-test and post-test was checked twice by the researcher. The intra- rater reliability was investigated using Pearson Product-moment correlation. There was a strong positive relationship between the calculations both at the pre-test $(\mathrm{r}=.88, \mathrm{p}<.05)$, and the post-test $(\mathrm{r}=89.5, \mathrm{p}<.05)$.

Table 1 shows the descriptive statistics for each of the for measures of fluency in the pre-test, such as mean, standard deviation, and standard error of the means regarding the performance of the participants in each group separately. It needs to be noted that since one of the participants in the control group was absent in the time of pre-test, the data from that learners was excluded in the final analysis. Therefore, the number of participants in the control group was reduced from 20 to 19.

TABLE1

DESCRIPTIVE STATISTICS FOR WRITING FLUENCY IN PRE-TEST

\begin{tabular}{llllll}
\hline & Groups & $\mathrm{N}$ & Mean & Std. Deviation & $\begin{array}{l}\text { Std. Error } \\
\text { Mean }\end{array}$ \\
Words per & control & 19 & 5.1184 & 1.593 & .365 \\
min .pre & experimental & 20 & 5.1970 & 1.882 & .420 \\
Words .pre & control & 19 & 203.37 & 60.422 & 13.862 \\
& experimental & 20 & 201.15 & 75.277 & 16.832 \\
Clauses .pre & control & 19 & 24.16 & 8.896 & 2.041 \\
& experimental & 20 & 23.60 & 8.191 & 1.832 \\
T-units .pre & control & 19 & 13.95 & 5.212 & 1.196 \\
& experimental & 20 & 15.05 & 4.904 & 1.097 \\
\hline
\end{tabular}

As the main aim of the study was to compare two means obtained from two groups of EFL learners, and since the independent variable in our study, that is, writing fluency had four levels, One-way ANOVA was used for the statistical analysis of the data both in the pre-test and post-test.Table 2 illustrates the results of ANOVA test for the comparison of groups regarding the four indicators of writing fluency in the pre-test.

TABLE2

RESULTS OF ANOVA TEST FOR WRITING FLUENCY IN PRE-TEST

\begin{tabular}{|c|c|c|c|c|c|c|}
\hline & & Sum of Squares & $\mathrm{df}$ & Mean Square & $\bar{F}$ & Sig. \\
\hline words & Between Groups & .060 & 1 & .060 & .020 & .889 \\
\hline \multirow[t]{2}{*}{ per min } & Within Groups & 113.076 & 37 & 3.056 & & \\
\hline & Total & 113.136 & 38 & & & \\
\hline \multirow{3}{*}{ words } & Between Groups & 47.952 & 1 & 47.952 & .010 & .920 \\
\hline & Within Groups & 173380.971 & 37 & 4685.972 & & \\
\hline & Total & 173428.923 & 38 & & & \\
\hline \multirow[t]{3}{*}{ clauses } & Between Groups & 3.033 & 1 & 3.033 & .042 & .840 \\
\hline & Within Groups & 2699.326 & 37 & 72.955 & & \\
\hline & Total & 2702.359 & 38 & & & \\
\hline \multirow[t]{3}{*}{ T-units } & Between Groups & 11.846 & 1 & 11.846 & .463 & .500 \\
\hline & Within Groups & 945.897 & 37 & 25.565 & & \\
\hline & Total & 957.744 & 38 & & & \\
\hline
\end{tabular}

As is shown in the table the performance of both experimental and control group in terms of writing fluency is similar in the pre-test. More specifically, for "words per minute" ( $\operatorname{sig}=.889, \mathrm{~F}=.020, \mathrm{p}<.05)$, with reference to "average number of words" ( $\operatorname{sig}=.920, \mathrm{~F}=.010, \mathrm{p}<.05)$, for "average number of clauses" ( $\operatorname{sig}=.840, \mathrm{~F}=.042$, $\mathrm{p}<.05)$, and for the last indicator of writing fluency namely, "average number of $\mathrm{T}$-units" $(\operatorname{sig}=.50, \mathrm{~F}=.463, \mathrm{p}<.05)$. Therefore, there was not a significant difference between control and experimental groups in terms of their writing fluency in the outset of the study.

Tables 3 and 4 express the results obtained from the analysis of the essays produced by the control and experimental groups in the post-test. Table 3 below shows the descriptive statistics for the four measures of writing fluency in the post-test. 
TABLE3

\begin{tabular}{llllll}
\hline & \multicolumn{4}{c}{ DESCRIPTIVE STATISTICS FOR WRITING FLUENCY IN POST-TEST } \\
\hline \multirow{3}{*}{ Words per } & groups & $\mathrm{N}$ & Mean & Std. Deviation & Std. Error Mean \\
min .post & control & 19 & 5.807 & 1.412 & .324 \\
Words .post & experimental & 20 & 7.084 & 2.296 & .513 \\
& control & 19 & 234.05 & 58.151 & 13.341 \\
Clauses .post & experimental & 20 & 287.45 & 85.236 & 19.059 \\
& control & 19 & 29.74 & 9.036 & 2.073 \\
T-units .post & experimental & 20 & 33.30 & 10.250 & 2.292 \\
& control & 19 & 17.84 & 4.670 & 1.071 \\
& experimental & 20 & 21.50 & 6.817 & 1.524 \\
\hline
\end{tabular}

Table 4 is illustrative of the results of ANOVA test ran in order to compare the performance of experimental and control group in the post-test.

TABLE4

RESULTS OF ANOVA TEST FOR WRITING FLUENCY IN POST-TEST

\begin{tabular}{|c|c|c|c|c|c|c|}
\hline & & Sum of Squares & $\mathrm{df}$ & Mean Square & $\mathrm{F}$ & Sig. \\
\hline words per & Between Groups & 15.892 & 1 & 15.892 & 4.321 & .045 \\
\hline \multirow[t]{2}{*}{$\min$} & Within Groups & 136.093 & 37 & 3.678 & & \\
\hline & Total & 151.985 & 38 & & & \\
\hline \multirow[t]{3}{*}{ words } & Between Groups & 27781.692 & 1 & 27781.692 & 5.168 & .029 \\
\hline & Within Groups & 198905.897 & 37 & 5375.835 & & \\
\hline & Total & 226687.590 & 38 & & & \\
\hline \multirow[t]{3}{*}{ clauses } & Between Groups & 123.706 & 1 & 123.706 & 1.321 & .258 \\
\hline & Within Groups & 3465.884 & 37 & 93.673 & & \\
\hline & Total & 3589.590 & 38 & & & \\
\hline \multirow[t]{3}{*}{ T-units } & Between Groups & 130.371 & 1 & 130.371 & 3.782 & .059 \\
\hline & Within Groups & 1275.526 & 37 & 34.474 & & \\
\hline & Total & 1405.897 & 38 & & & \\
\hline
\end{tabular}

As is indicated in the table experimental group outperformed the control group in some aspects of the writing fluency, however in one of the measures the table does not show a significant difference between the two groups. To put it more specifically, experimental group had outperformed control group with regard to "words per minute" (sig=.045, $\mathrm{F}=4.321$, $\mathrm{p}<.05$ ), "average number of words" ( $\mathrm{sig}=.029, \mathrm{~F}=5.168, \mathrm{p}<.05)$, and "average number of T-units" ( $\mathrm{sig}=.059, \mathrm{~F}=3.728$, $\mathrm{p}<.05)$. But, as to the third measure of writing fluency which is "average number of clauses" the table does not show any significant difference ( $\mathrm{sig}=.258, \mathrm{~F}=1.32, \mathrm{p}<.05$ ). Since not all the indicators of writing fluency showed a significant difference between the experimental and control group, we cannot strongly reject the first null hypothesis.

In order to analyze data for the second and third objectives of the study namely exploring whether there is an improvement in the writing fluency of competent and less competent learners in the experimental group, the means of words written per minute, words, clauses and T-units was compared for competent and less competent learners, separately. For this purpose repeated measures ANOVA was used to compare the performance of competent and less competent writers in terms of their writing fluency in Time (1) prior to treatment and Time (2) after the treatment. Table 5 shows descriptive statistics for the essays of 10 competent writers in the experimental group, who were supposed to provide scaffolding for their peer writers, in the pre-test and post-test.

TABLE5

RESULTS OF DESCRIPTIVE STATISTICS FOR WRITING FLUENCY OF COMPETENT WRITERS

\begin{tabular}{llll}
\hline & Mean & Std. Deviation & $\mathrm{N}$ \\
Words per minute1 & 5.971 & 2.102 & 10 \\
Words per minute2 & 7.961 & 2.590 & 10 \\
Words1 & 248.40 & 79.126 & 10 \\
Words 2 & 328.60 & 93.086 & 10 \\
Clauses1 & 29.50 & 7.472 & 10 \\
Clauses2 & 36.70 & 11.036 & 10 \\
T-units1 & 18.00 & 5.099 & 10 \\
T-units2 & 22.70 & 7.718 & 10 \\
\hline
\end{tabular}

Table6 shows the within subjects effects for the writing fluency of competent writers.

TABLE6

WITHIN SUBJECT EFFECT FOR WRITING FLUENCY OF COMPETENT WRITERS

\begin{tabular}{llllll}
\multicolumn{5}{c}{ WITHIN SUBJECT EFFECT FOR WRITING FLUENCY OF COMPETENT WRITERS } \\
\hline Source & $\begin{array}{l}\text { Type III Sum } \\
\text { of Squares }\end{array}$ & df & Mean Square & F & Sig. \\
Words per minute & 20.869 & 1 & 20.869 & 11.438 & .008 \\
Words & 41678.450 & 1 & 41678.450 & 20.209 & .001 \\
Clauses & 684.450 & 1 & 684.450 & 14.596 & .004 \\
T-units & 336.200 & 1 & 336.200 & 17.212 & .002 \\
\hline
\end{tabular}

Note: sphericity is assumed 
The results demonstrated that there was a significant effect for all the four indicators of writing fluency. To put it more specifically, for "words per minute" ( $\operatorname{sig}=.036, \mathrm{~F}=6.024, \mathrm{p}<.05$ ), for "average number of words" (sig=.016, $\mathrm{F}=8.86, \mathrm{p}<.05$ ), for "average number of clauses" ( $\mathrm{sig}=.040, \mathrm{~F}=5.77, \mathrm{p}<.05)$ and for "average number of $\mathrm{T}$-units" ( $\mathrm{sig}=.051, \mathrm{~F}=5.07, \mathrm{p}<.05)$. Accordingly the second null hypothesis postulated is rejected.

Table 7 reveals the descriptive statistics for the writing performance of less competent writers in the pre- and posttests, and Table 8 shows within subject effects for less competent writers.

TABLE7

DESCRIPTIVE STATISTICS FOR WRITING FLUENCY OF LESS COMPETENT WRITERS

\begin{tabular}{llll}
\hline & Mean & Std. Deviation & $\mathrm{N}$ \\
Words per minute1 & 4.165 & .911 & 10 \\
Words per minute2 & 6.208 & 1.647 & 10 \\
Words1 & 154.80 & 31.290 & 10 \\
Words 2 & 246.10 & 54.321 & 10 \\
Clauses1 & 18.20 & 4.23 & 10 \\
Clauses2 & 29.90 & 8.621 & 10 \\
T-units1 & 12.10 & 2.331 & 10 \\
T-units2 & 20.30 & 5.945 & 10 \\
\hline
\end{tabular}

TABLE8

Within SubJect EFFect For Writing FLUENCy Of Less COMPETENT Writers

\begin{tabular}{llllll}
\hline Source & Type III Sum of Squares & $\mathrm{df}$ & Mean Square & $\mathrm{F}$ & Sig. \\
Words per minute & 19.801 & 1 & 19.801 & 6.024 & .036 \\
Words & 32160.200 & 1 & 32160.200 & 8.860 & .016 \\
Clauses & 259.200 & 1 & 259.200 & 5.777 & .040 \\
T-units & 110.450 & 1 & 110.450 & 5.070 & .051 \\
\hline \multicolumn{5}{c}{ Note: sphericity is assumed }
\end{tabular}

As is evident in the table, the results indicated that in case of less competent writers also there was a significant effect for all the four indicators of writing fluency. In other words, regarding "words per minute" (sig= .008, $\mathrm{F}=11.438$, $\mathrm{p}<.05$ ), for "average number of words" ( $\mathrm{sig}=.001, \mathrm{~F}=20.209, \mathrm{p}<.05$ ), for "average number of clauses" ( $\mathrm{F}=14.596, \mathrm{p}<.05)$ and for "average number of T-units" ( $\mathrm{sig}=.002, \mathrm{~F}=17.212, \mathrm{p}<.05)$. Therefore, the third null hypothesis is also rejected.

\section{DisCUSSION AND CONCLUSION}

This study aimed at investigating the impact of peer scaffolding trough process approach on the writing fluency of EFL learners. To this purpose two groups of university EFL students majoring in English Language and Literature took part in a series of argumentative writing classes. One group (Control) was taught based on the traditional product approach to writing, whereas the other group (Experimental) received instruction based on process approach to writing while the learners wrote in pair and one them, that is, the competent writer provided scaffolding to the other one. Since the main aim of providing scaffolding is to lead the learners to a path in which he or she can complete a task individually, at the end of the classes each learner both in the control and experimental group was required to write an argumentative essay individually which was also used as the post-test.

Regarding the first Research Question that is "what is the impact of peer scaffolding through process approach on writing fluency of EFL learners?" it can be concluded from the results of one-way ANOVA that although, peer scaffolding may have an influence on the amounts of words produced per minute $(\mathrm{p}=.04)$, or the average number of words produced $(\mathrm{p}=.02)$ and the average $\mathrm{T}$-units written $(\mathrm{p}=.05)$, it does not have any significant effect on the average number of clauses produced by the learners $(\mathrm{p}=.25)$. Therefore, since not all of the indicators of writing fluency, as it was defined and used in the present study, expressed a significant improvement regarding the pre- and post-test of writing, the first null hypothesis cannot be rejected, and the statistical analyses show that peer scaffolding through process approach does not have any significant impact on developing writing fluency of EFL learners. This result is in line with the study of Wiggleworth \& Storch (2009), based on which the performance of individuals and pairs were similar across the sub-measures of writing fluency.

Referring to the second Research Question which is "does peer scaffolding through process approach have any influence on writing fluency of competent learners?" the results of Repeated Measures ANOVA revealed that there was a significant difference between the writing fluency of competent learners in the pre- and post-test of writing. More specifically, competent learners produced more words per minute $(\mathrm{p}=.036)$, and also the average number of words produced by them was greater than the pre-test $(\mathrm{p}=.016)$, they also wrote more clauses $(\mathrm{p}=.040)$ and more $\mathrm{T}$-units $(\mathrm{p}=.051)$. Accordingly, the second null hypothesis is rejected and peer scaffolding through process approach is shown to have a significant effect on writing fluency of competent writers.

Considering the third Research Question which is "does peer scaffolding through process approach have any influence on writing fluency of less competent learners?" Repeated Measures ANOVA showed that less competent writers have improved in their writing performance in terms of writing fluency. To put it more specifically, less competent writers produced more words per minute $(\mathrm{p}=.008)$, also the average number of words $(\mathrm{p}=.001)$, clauses 
( $\mathrm{p}=.004)$, and T-units ( $\mathrm{p}=.002)$ have increased in the writing performance of these learners. Consequently, the third null hypothesis can be rejected, and it can be concluded that less competent learners have benefited from peer scaffolding through process approach as they wrote more fluently after the experiment.

Overall, on the basis of the obtained results we can conclude that although having the EFL learners to write in pair while one of them provides scaffolding for the other one, may not influence their writing fluency as a whole, it can have significant impact on the writing fluency of those who provide scaffolding and those who receive it. As writing fluently is one of the most important requirements of students in an academic EFL context, and since there are a great number of students in the classes, the application and use of peer scaffolding can be a valuable asset for EFL teachers.

Further research is needed in order to investigate the impact of peer scaffolding through process approach on other dimensions of writing skill, such as writing accuracy or complexity. Additionally, other research studies can be conducted to explore the probable impacts that peer scaffolding can have on the development of other language skills such as Listening, Speaking and Reading. Finally, as the present study was conducted in an academic context and with intermediate level students, further research is needed to be done in other learning contexts considering other proficiency levels.

\section{REFERENCES}

[1] Anton, M. (1999).The discourse of learner-centered classroom: Sociocultural perspectives on teacher-learner interaction in the second language classroom. The Modern Language Journal, 8, 303-318.

[2] Barnard, R. (2002). Peer tutoring in the primary classroom: A sociocultural interpretation of classroom interaction. New Zealand Journal of Educational Studies, 37(1), 57-72.

[3] Barnard, R. \& Campbell, L. (2005). Sociocultural theory and the teaching of process writing: The scaffolding of learning in a university context. The TESOLANZ Journal, 13, 76-88.

[4] Bruner, J. (1978). The role of dialogue in language acquisition. In A. Sinclair, R. J. Jarvella \& W. Levelt (Eds.), The child's concept of language. New York: Springer-Verlag.

[5] Donato, R. (1994). Collective scaffolding in second language learning. In: J.P. Lantolf \& G., Appel (Eds.), Vygotskian approaches to second language research. Norwood, NJ: Albex.

[6] Hekamäki, L. (2005). Scaffolded assistance provided by EFL teacher during whole class interaction. Unpublished PhD thesis. University of Jyväskyalä, Jyväskyalä.

[7] Lantolf, J. (2000). Second language learning as a mediated process. Language Teaching, 33, 79-96.

[8] Lantolf, J. P. \& Thorne, S. L. (2006). Sociocultural theory and the genesis of second language development. Oxford: Oxford University Press.

[9] Lantolf, J. P. \& Thorne, S. L. (2007). Sociocultural theory and second language learning. In B.V. Patten \& J. Williams (Eds.), Theories in second language acquisition. Cambridge: Cambridge University Press.

[10] Mirzaee, A, Domakani, M. R. \& Roshani, N. (2010). L2 discourse co-construction within the learner's ZPD. The Journal of Teaching Language Skills, 2, 91-115.

[11] Pishghadam, R. \& Ghadiri, S. (2011). Symmetrical or asymmetrical scaffolding: Piagetian vs. Vygotskyan views to reading comprehension. Journal of Language and Literacy Education, 7(1), 49-64.

[12] Riazi, M. \& Rezaii, M. (2010). Teacher- and peer scaffolding behaviors: Effects on EFL students' writing improvement. In A. Feryok (Ed.) CLESOL 2010: Proceedings of the $12^{\text {th }}$ National Conference for Community Language and ESOL.

[13] Smalley, R.L., Ruetten, M.K. \& Kozyrev, J.R. (2001). Refining composition skills. Boston, Massachusetts: Heinle \& Heinle publishers.

[14] Storch, N. (1999). Are two heads better than one? Pair work and grammatical accuracy. System, 27, 363-347.

[15] Storch, N. (2005). Collaborative writing: Product, process, and students' reflections. Journal of Second Language Writing, 14, 153-173.

[16] Storch, N. (2007). Investigating the merits of pair work on a text editing task in EFL classes. Language Teaching, 11, 143-159.

[17] Tsai, Y.C. (2006). The effects of asynchronous peer review on university students' argumentative writing. Unpublished PhD thesis. University of Maryland.

[18] Van Lier, L. (2004). The ecology and semiotic of language learning: A sociocultural perspective. NY: Kluwer Academic Publishers.

[19] Vygotsky, L. S. (1978). Mind in society: The development of higher psychological process. Cambridge: Harvard University Press.

[20] Vygotsky, L. S. (1981). The genesis of higher mental functions. In J.V. Werstch (Ed.) The concept of activity in Soviet psychology. Armonk, NY: M.E. Sharpe.

[21] Vygotsky, L. S. (1987). Thinking and speech. In L. S. Vygotsky, Collected works (pp. 39-285), R. Rieber\& A. Carton (Ed.), New York:Plenum.

[22] Walqui, Aida. (2006). Scaffolding instruction for English language learners: A conceptual framework. The International Journal of Bilingual Education and Bilingualism. 9(2), 159-180.

[23] Wells, G. (1998). Using L1 to Master L2: a response to Anton and Dicamilla's sociocognitive functions of L1 collaborative interaction in the L2 classroom. Canadian Modern Language Review. 54, 343-353.

[24] Wiggleworth, G. \& Storch, N. (2009). Pair versus individual writing: Effects on fluency, complexity and accuracy. Language Testing, Vol 26(3), 445-466.

[25] Wood, D., Bruner, J.S. \& Ross, G. (1976). The role of tutoring in problem solving. Child Psychology, 17, 89-100. 
Masoud Khalili Sabet is Assistant Professor of TEFL and the assistant director of research and technology at University of Guilan, Rasht, Iran. His research interests include advanced writing, methodology of language teaching, language teaching in practice, and testing.

Abdorreza Tahriri is Assistant Professor of TEFL at University of Guilan, Rasht, Iran. He has many publications and conference presentations on different subjects related to TEFL. His main areas of interest include differentiated instruction, critical thinking and computer-assisted language learning.

Parastou Gholami Pasand is an M.A. student of TEFL at University of Guilan, Rasht, Iran. Her research interest includes Language skills and components, learning strategies, curriculum development and Sociocultural Theory. 